\title{
A POLÍTICA EXTERNA INDEPENDENTE (PEI): ANTECEDENTES, APOGEU E DECLÍNIO
}

\author{
Tânia Maria P. G. Manzur
}

No período de 1961 a 1964, governaram o Brasil, sucessivamente, Jânio Quadros e João Goulart. Evidenciou-se, naquele momento, um processo de gestação, desenvolvimento, apogeu e, por fim, o rápido declínio da Política Externa Independente (PEI), estruturada em conjunto por Quadros e Afonso Arinos, sistematizada posteriormente por San Tiago Dantas e em seus estertores solapada pela ocorrência do golpe militar de 1964. Nesse curto período, elementos comuns podem ser identificados entre as gestões de Quadros e Goulart. Em primeiro lugar, a existência de um eixo central na inserção internacional do Brasil, a partir da Política Externa Independente, proposta que projetava para o país relações internacionais sem constrangimentos ideológicos em um momento de Guerra Fria, no qual, para muitos, essa independência não seria viável nem sequer possível. Em segundo, o envolvimento da opinião pública com assuntos de política exterior, envolvimento esse fruto da evolução de uma política populista já identificável, por exemplo, com Getúlio Vargas e Juscelino Kubitschek, em anos anteriores. Ao populismo aliaram-se 
o desenvolvimento e a disseminação dos meios de comunicação de massa (especialmente o rádio e a televisão), o aumento dos níveis de alfabetização da população brasileira, acompanhado da crescente urbanização. A tudo isso, associou-se a noção, ainda que incipiente e não ilustrada de grande parte da população, da existência de um "inimigo" internacional nas Américas (e, na visão ocidentalista, no mundo inteiro): o perigo comunista. $\mathrm{O}$ governo informava a população e a opinião pública, a seu turno, discutia e se manifestava acerca da inserção internacional do país. Grosso modo, entre 1961 e 1964, confrontavam-se, a partir da expressão das diferentes correntes de opinião pública no Brasil, visões as mais diversas sobre a forma como a nação deveria apresentar-se no cenário internacional.

A partir dos embates entre as diferentes correntes, deu-se uma paulatina polarização da opinião pública nacional nos anos finais do governo Goulart. Houve uma radicali170 zação entre, por um lado, os que preconizavam relações especiais com a potência norte-americana, o ocidentalismo, a liberalização do comércio e, por outro, os que veementemente lutavam contra o "imperialismo ianque", a dependência em relação aos Estados Unidos e a favor do nacionalismo, mesmo em política exterior, da autonomia internacional do Brasil, da abertura a relações mais próximas com países socialistas e comunistas. Como já observado e documentado em obra de minha autoria, a polarização das tendências de opinião foi um dos fatores que contribuíram decisivamente para o golpe de 1964, tendo prevalência nesse aqueles que preconizavam o primeiro grupo, que chamamos de liberal-ocidentalistas.

Ocorre que toda essa movimentação se deu exatamente em um período de Guerra Fria, em momento no qual as superpotências fortaleciam, cada uma em um polo, seus condomínios de poder, sedimentando os dois blocos antagônicos estruturados sobre as escolhas econômicas, estraté- 
gicas, militares, culturais, ideológicas e políticas dos diferentes lados. O desenvolvimento, apogeu e declínio das ideias singularizadas e postas em prática pelos líderes da PEI se deram, portanto, no âmbito de um contexto à primeira vista desfavorável ou, no mínimo, pouco condizente com qualquer proposta independentista: havia essencialmente dois blocos de poder e o mundo era convidado a escolher um dos extremos. Era, portanto, aparentemente complexo e contraditório com a realidade internacional trabalhar na perspectiva da independência em relação aos blocos, mas foi isso que Quadros e Goulart procuraram empreender com a PEI. Essa aparente discrepância foi um dos fatores que levaram ao declínio da referida política, uma vez que grupos sociais e econômicos prevalentes na sociedade brasileira da época encontravam vasta justificação para a adesão ao bloco ocidental em detrimento de qualquer autonomia que o governo propusesse.

Pretende-se neste artigo analisar os principais antecedentes da PEI, o contexto internacional em que ela se inseriu e as principais características do desenrolar de sua implementação. Ademais, como fundamento para a compreensão do declínio da PEI será também, ainda que brevemente, abordada a relação entre política exterior e opinião pública à época.

\section{Fundamentos históricos da PEI}

Em 1930, tendo Getúlio Vargas ascendido ao poder no Brasil, delineou-se uma percepção inovadora das relações internacionais, em que um eixo central passou a pautar a política externa do país, até o fim dos governos militares, com alguns resquícios evidenciando-se, até fins dos anos 1980: o nacional-desenvolvimentismo. Não se trata de uma teoria, doutrina ou processo, pois que não houve, à época de sua vigência, formulação teórico-metodológica que lhe fornecesse uma explicação racional, empírica; tampouco 
se procurou deliberadamente enquadrar as finalidades da política externa nesta ou naquela categoria. O termo veio à tona na historiografia de Relações Internacionais do Brasil com a obra seminal de Gérson Moura, que tratava principalmente da política exterior implementada pelo Brasil no governo de Juscelino Kubitschek, quando se privilegiou o contexto externo na solução dos problemas nacionais (Moura, 1980). Note-se a esse respeito que, a despeito da grande relevância e novidade da percepção de Moura, podem-se identificar as raízes desse modelo já no primeiro governo de Getúlio Vargas, a partir do qual se tem uma concepção objetiva e pragmática da política exterior do Brasil. Compreender o nacional-desenvolvimentismo é, portanto, ir à essência da política exterior que se empreendeu no Brasil pelo menos a partir dos anos 1930; pode-se perceber, nesse mister, um ponto de inflexão na concepção brasileira de relações internacionais.

172 O nacional-desenvolvimentismo pode ser entendido, em uma interpretação livre do pensamento de Moura, como a busca do desenvolvimento interno pela via da política externa. Nessa linha de pensamento, identificam-se, na política externa, os meios para se viabilizar a suplantação ou a eliminação dos obstáculos ao desenvolvimento, ou ao menos para a superação do subdesenvolvimento. Vargas foi, nesse sentido, o primeiro líder brasileiro a encampar a ideia de que a barganha internacional poderia tornar viáveis projetos como o da modernização das Forças Armadas, da economia e das finanças do país, e da implantação da indústria siderúrgica, estabelecendo as bases para o crescimento nacional. Tendo em vista seus objetivos, Vargas deu o tom de uma nova linha de conduta para a política exterior do Brasil, estabelecendo uma tendência que se fez presente também quando da elaboração da PEI.

De modo resumido, pode-se afirmar que a política exterior no primeiro governo de Vargas (1930-1945) teve 
em seu bojo práticas notoriamente elaboradas com vistas a angariar benefícios para o desenvolvimento nacional, entre as quais está a ênfase nas relações comerciais, marcada por grande ímpeto governamental na "regularização" ou na regulamentação de tais relações. Essa tendência, a bem da verdade, já se evidenciava na política exterior empreendida por Rio Branco (1902-1912), mas com Vargas tomava contornos diferentes no que tange às finalidades, conforme já mencionado. Gérson Moura considera esse um período de autonomia na dependência, dado que o Brasil não detinha base de poder para se desvincular das potências da época, mas buscava construir relativa autonomia decisória, o que ficou patente com a equidistância pragmática, especialmente entre 1935 e 1942 (Cervo e Bueno, 2011; Moura, 1980). Essa linha de ação capitaneada por Vargas presumia uma busca de diversificação da pauta comercial brasileira, dominada pela exportação de café, e pragmatismo nas relações políticas e estratégicas, especialmente até o início da Segunda Guerra Mundial. Com a eclosão da guerra, a equidistância que Vargas procurou sustentar, ora pendendo para o lado dos Estados Unidos, ora para o da Alemanha, foi-se tornando paulatinamente insustentável, até que as lideranças políticas decidiram-se pelo lado das potências ocidentais, não sem antes assegurar a viabilidade, com apoio principalmente dos Estados Unidos, da implantação da indústria de base no Brasil e da modernização das Forças Armadas nacionais (Manzur, 2009a).

O primeiro governo Vargas saiu de cena concomitantemente ao fim da Segunda Guerra; naquele momento, verificou-se que os interesses norte-americanos se voltaram basicamente para a contenção do avanço comunista no mundo. Para tanto, os Estados Unidos se empenharam na reconstrução europeia e redobraram as atenções em regiões conflituosas como partes da Ásia, do Oriente Médio e da África, onde vários países conquistavam a independência; na visão 
do governo norte-americano, a instabilidade poderia atrair investidas do comunismo e fazer que parecessem sedutoras a economia e sociedade planificadas da União Soviética (Arnold e Wiener, 2012).

Por essa razão, os Estados Unidos tomaram diversas iniciativas para barrar o avanço da ideologia socialista/comunista em áreas que, a princípio, na divisão internacional de poder, estariam sob influência norte-americana. Cuidou-se, então, de montar um escudo anticomunista, mormente na Europa, mas com reflexos para o resto do mundo, com as seguintes realizações: a) O Plano Marshall, de cunho econômico-financeiro, com vistas à reconstrução das áreas devastadas pela guerra. Em essência, esse Plano redundou em ajuda econômica e financeira norte-americana para a reconstrução da Europa. Ademais, a própria lógica do capitalismo de então favorecia a recomposição dos mercados europeus destruídos para que se fortalecessem futuramente e se renovas-

174 sem de forma a reassumir seu posto de parceiro privilegiado dos Estados Unidos. b) A Organização do Tratado do Atlântico Norte (Otan), aliança defensiva que representava o braço estratégico-militar do conjunto de ações da política exterior norte-americana, que refletia a relevância crescente da concepção de segurança coletiva nas relações internacionais; e c) a Doutrina Truman, fundamentalmente uma proposição político-ideológica, que dava tônus a diferentes formas de combater o comunismo internacional. A vertente ideológica da ação estadunidense era impulsionada pela Doutrina Truman, segundo a qual a verdadeira ameaça ao mundo livre se chamava comunismo internacional, cujo maior mentor e difusor era a União Soviética (Truman, 1947). Essa perseguição acirrada ao comunismo, concomitante ao processo de ajuda econômico-financeira e ao apoio militar à Europa acabou por sedimentar em áreas sob a égide da superpotência norte-americana o temor do avanço comunista (Moura, 1991, pp. 53-59; Manzur, 2009b, pp. 70-72). 
Resta claro que a União das Repúblicas Socialistas Soviéticas (URSS) procurava agir com intensidade semelhante para barrar o avanço do capitalismo sobre suas áreas de influência já estabelecidas desde Yalta, Teerã e Potsdam. A URSS recrudesceu, com isso, as fronteiras na Europa do Leste; esforçou-se para expandir o socialismo nas regiões turbulentas da África e da Ásia; empreendeu avanços na área militar e estratégica (principalmente com a definitiva confecção de sua bomba nuclear ainda em 1949); impulsionou a formação do Pacto de Varsóvia, aliança militar dos países socialistas com o mesmo fundamento de segurança coletiva que a Otan; enfim, tentou assegurar seu predomínio nas regiões que, na realidade da Guerra Fria, lhe cabiam como áreas de influência, satélites ou aliadas (The Cominform, 1994; Muresan, 2008).

A América Latina, na divisão dos condomínios de poder, ficaria naturalmente na órbita de influência dos Estados Unidos, seja em razão da localização geográfica, seja tendo em vista a afinidade já historicamente singularizada da americanidade, ou do americanismo. De fato, essa ideologia americanista era reforçada - do lado norte-americano - desde o século XIX pelas conferências pan-americanas e posteriormente pela Doutrina Monroe e pelo Corolário Roosevelt. E encontrava eco nos vizinhos continentais. Ocorre que, no pós-Segunda Guerra, os Estados Unidos voltaram para outras regiões seus esforços de contenção do avanço comunista e, com isso, seus investimentos, estratégias, ações de política exterior mais relevantes. Descuidaram, portanto, daquela sua "aliada natural". Isso se deve essencialmente ao fato de que as Américas foram, como um todo, alvo da propaganda ideológica norte-americana e não seriam, portanto, na visão estadunidense da época, passíveis de contaminação pela ideologia inimiga, pelo simples fato de estarem na área de influência dos Estados Unidos, de forma inquestionável e inequívoca (Vaïsse, 2002, p. 46). 
A situação no Brasil não era diferente daquela de outros países americanos. Logo após a Segunda Guerra Mundial, ainda em 1946, o general Eurico Gaspar Dutra assumiu, democraticamente, a presidência do país. Procedeu, em sua política exterior, a um alinhamento automático com os Estados Unidos, para muitos decorrente da opção ocidental, mais especificamente pelo fato de o Brasil ter apoiado os Aliados (e, em primeira instância, os Estados Unidos) durante a mencionada guerra. O governo do presidente Dutra era conservador tanto na esfera externa como na interna. Na via diplomática, o governo estreitava seus laços com a política norte-americana, rompendo relações diplomáticas e comerciais com a União Soviética e, posteriormente, com a China, a partir da instauração do regime comunista naquele país.

Na seara econômica, Dutra procedeu a uma abertura comercial que acabou por esgotar as parcas reservas 176 nacionais, em nome de um relacionamento especial com a superpotência ocidental. No campo estratégico, o Brasil empreendeu cooperação militar com os Estados Unidos, potencializando o alinhamento político entre os dois países e fortalecendo os laços de relacionamento continental e de obediência à linha política externa defendida por aquela nação com o Tratado Interamericano de Assistência Recíproca (TIAR), assinado no Rio de Janeiro, em 1947 (Cervo e Bueno, 2011, pp. 289-92; Skidmore, 1975, p. 121).

De qualquer modo, malgrado as iniciativas brasileiras, não se percebia contrapartida do governo norte-americano. Não vieram investimentos, nem incrementos à indústria, nem cooperação internacional nos níveis esperados, para o Brasil e para toda a América Latina. Isso alimentou ainda mais o sentimento contrário à vinculação especial com os Estados Unidos. Temia-se que o imperialismo estadunidense pudesse ser ainda mais nefasto que qualquer ameaça comunista. 
Foi nesse quadro que ascendeu ao poder, novamente, Getúlio Vargas, então pelo voto popular, quando já estava efervescendo no país o populismo, que se estendeu como característica da política brasileira até o golpe militar de 1964. A propósito, o populismo foi um fenômeno típico da política latino-americana, surgido após a Segunda Guerra Mundial. Para Francisco Weffort (1980, texto da aba), o fenômeno do populismo que vigorou no Brasil e em outros países da América Latina durante várias décadas representou "uma forma de militância política que envolveu e mobilizou grandes massas, principalmente urbanas, dos estratos mais humildes da população, setores operários e da pequena burguesia das cidades e do campo". Tem lugar em realidades políticas nas quais "a estrutura de poder oligárquica está em crise; quando as classes dominantes se sentem incapazes de manter-se no poder, mediante procedimentos eleitorais tradicionais”. É nessas circunstâncias que os líderes populistas "acenam com promessas de abundância distributivista ou de moralidade administrativa, atraindo as camadas mais despojadas da população e uma nova clientela de setores médios em ascensão”. Com promessas e afirmações categóricas, tais líderes mostram um perfil "paternalista e carismático, conseguindo empolgar as massas populares recém-urbanizadas, que desejam uma solução não radical para a melhoria de suas condições de vida, ou camadas médias ascendentes com objetivos próprios de mobilidade social". Essa linha de conduta política fortaleceu-se no segundo governo Vargas (de 1951 a 1954), impactou o modo de fazer política exterior e teve profundas repercussões durante a vigência da PEI, como se verá adiante neste artigo.

Por ocasião da nova ascensão de Vargas ao poder, e dado o populismo característico do período, emergiu um feroz embate entre correntes internas de opinião, acerca da forma como o Brasil deveria inserir-se no cenário internacio- 
nal. As duas principais correntes de pensamento expressas na sociedade brasileira, nacionalistas e "entreguistas", divergiam essencialmente sobre como o Brasil deveria inserir-se no cenário internacional: os "entreguistas" acreditavam na necessidade de abrir a economia nacional ao capital externo. Só seguindo essa tendência o Brasil teria condições de superar o subdesenvolvimento. É claro que, sendo os Estados Unidos a grande potência americana, com a qual o Brasil já mantinha relações especiais, uma decorrência natural da abertura comercial seria o incremento de relações com aquele país. Com isso, o parceiro, que já era preferencial, tornar-se-ia ainda mais próximo. Na visão dos "entreguistas", qualquer protecionismo e qualquer interferência do Estado na economia deveriam ser combatidos de forma a tornar o Brasil um país atraente aos investimentos externos. Para que a incipiente indústria brasileira se tornasse competitiva, seria necessário muito tempo e investimento estrangeiro, bem 178 como muita substituição de importações, somente alcançável se o Brasil passasse a importar mais.

A visão nacionalista, por sua vez, destoava frontalmente da "entreguista". Primeiro, temia todas as formas de investimento estrangeiro que pudessem causar dependência. Nessa visão, uma abertura comercial irrestrita para os Estados Unidos seria a porta de entrada mais permissiva para a ingerência norte-americana em assuntos internos brasileiros. Além disso, dada a pujança da economia estadunidense, seria um perigo abrir a economia brasileira, já que a consequência natural para esta seria a crescente dependência em relação àquela. Não que o capital estrangeiro fosse de todo abominável, mas, por princípio, ofereceria perigos. Indesejável seria qualquer ingerência de capital que causasse a dependência. Outro elemento de divergência dizia respeito à produção nacional: toda a indústria brasileira deveria, na visão nacionalista, promover o crescimento pela via do reinvestimento dos lucros localmente auferidos. Isso certa- 
mente não ocorria nem ocorreria no caso de uma indústria estrangeira produzindo em solo nacional, já que a maior parcela dos lucros seria sempre remetida ao exterior. Não havendo no Brasil legislação suficientemente forte para combater os excessos de remessas de lucros, os nacionalistas viam com receio e rejeitavam a abertura proposta pelos "entreguistas" (Manzur, 1999, pp. 49-50).

O embate entre as mencionadas correntes de opinião interna perdurou por todo o segundo governo Vargas, até a morte do presidente. Para alguns analistas, o fato de Vargas não conseguir gerenciar os embates entre as duas vertentes opostas pode ser considerado uma das causas de sua queda. A tentativa de política pendular desagradou aos dois lados e, tendo em vista que Vargas não tinha maioria no Congresso, acabou por ensejar duros e constantes ataques da oposição udenista e pessedista, liderada, principalmente, por Carlos Lacerda, histórico "destruidor de presidentes" (Skidmore, 1975, pp. 174-80).

Em seguida à morte de Vargas, observou-se um rearranjo das correntes de opinião, que veio a evidenciar-se com maior clareza nos governos de Jânio Quadros e João Goulart. Ressalte-se que o sentimento anti-ianque foi se tornando cada vez mais forte no Brasil, como em outras partes da América, e foi com base nisso que Juscelino Kubitschek empreendeu um dos mais denodados projetos de política exterior já evidenciados na história brasileira.

No governo de Kubitschek, o nacional-desenvolvimentismo ficou mais evidente, mais nítido, tendo sido explicitamente estabelecido como fundamento da política externa. Soluções para problemas nacionais eram buscadas no contexto externo e o projeto de desenvolvimento nacional baseava-se em uma política de atração do capital estrangeiro favorecida pela conjuntura internacional: na América Latina, em especial, recrudescia a decepção pela falta de atenção norte-americana ao continente; com isso, afloravam os 
nacionalismos, o antiamericanismo e o anti-imperialismo. Juscelino Kubitschek procurou fazer conviverem duas tendências relevantes: acelerado crescimento industrial (com alinhamento automático em relação a Washington) e nacionalismo. De certo modo, procurava superar os antagonismos evidenciados no governo Vargas com um discurso desenvolvimentista que tinha o fito de unificar, dentro das possibilidades, forças políticas e socioeconômicas brasileiras em prol da superação do subdesenvolvimento nacional, da modernidade e da projeção internacional mais assertiva do país. O processo de industrialização dependia do capital estrangeiro e ajustou-se aos interesses emanados da grande potência norte-americana. Desse modo, o governo JK marcou o grande ímpeto ao modelo de desenvolvimento industrial do Brasil com a penetração de capital estrangeiro de forma maciça e, principalmente, no ramo das indústrias pesadas como a automobilística, a elétrico-eletrônica, a quí180 mica, a farmacêutica e a de eletrodomésticos, entre outras que se configuram como setores dinâmicos da economia (Manzur, 1999, pp. 51-52).

Mesmo assim, Kubitschek procurou não descuidar da cooperação internacional como alternativa para alcançar, de modo menos dependente possível, o desenvolvimento nacional. Deu grande ênfase às relações de cooperação multilateral, o que ficou explícito por ocasião da proposição da Operação Pan-Americana (OPA), em 1958. A OPA relacionava explicitamente a instabilidade política resultante da pobreza e do subdesenvolvimento existentes no continente latino-americano à possibilidade de colapso da ordem capitalista na região. Entretanto, apesar da iniciativa de JK, não chegou a convencer o presidente norte-americano de sua premência até o advento da Revolução Cubana, em 1959. O governo instaurado após a Revolução, liderado por Fidel Castro, em pouco tempo tomou matizes socialistas, rompeu com os Estados Unidos em 1960 e reavivou o temor de que 
o avanço comunista se estendesse por todo o continente (Cervo e Bueno, 2011, pp. 311-17; Lessa, 2008; Mello e Silva, 1992). Com isso, realçou-se para os norte-americanos a necessidade de recorrer à noção de segurança coletiva com base na solidariedade continental, a fim de não permitir que em seus "quintais" se promovesse o avanço tão evidente da ideologia soviética.

Tomando as reações latino-americanas como pretexto, Juscelino Kubitscheck elaborou um programa de desenvolvimento econômico, social e político para a região (Lessa, 2008). Entretanto, não se restringiu apenas ao contexto regional, pautando também sua política exterior pela busca do desenvolvimento econômico nacional com bases pragmáticas, sem necessárias vinculações ideológicas. Essa percepção se revelou no reatamento das relações comerciais com a URSS - já visualizando, inclusive, a possibilidade do reatamento das relações diplomáticas interrompidas em 1945 -, e numa tentativa de desviar o olhar da opinião pública sobre a escalada inflacionária, decorrente ela própria da dependência em relação ao capital estrangeiro, entre outros fatores, e rompeu com as imposições da vinculação à política monetária do Fundo Monetário Internacional (FMI), em 1959. Deixou, com isso, os problemas da inflação e da dívida externa para seu sucessor gerenciar (Skidmore, 1975, p. 224).

Uma vez delineados os principais antecedentes da política exterior que se cunhou no Brasil a partir de 1961, é relevante apontar para o fato de que algumas das pretensas inovações apresentadas na PEI já vinham sendo sugeridas ou ao menos cogitadas em governos anteriores. Como demonstrado, o nacional-desenvolvimentismo já era o fio condutor da política externa brasileira desde o primeiro governo Vargas; o alargamento da pauta comercial brasileira, inclusive por meio da diversificação dos parceiros internacionais, também advém de tempos anteriores, 
tendo tomado impulso com Juscelino; a própria busca de independência e de desvinculação automática em face dos polos ideológicos é também uma ideia presente, ainda que não plenamente concretizada, nos governos anteriores. De todo modo, seguiremos agora para uma compreensão mais detalhada do que foi a PEI, sem perder de vista, reiteramos, que toda a inovação nela embutida se refere muito mais ao processo de implementação do que ao de elaboração do processo decisório de política externa. A título de esclarecimento, consideramos aqui elaboração a fase do processo decisório em que os decision-makers concebem e estruturam as ações de política exterior, tendo em vista os interesses relevantes socialmente sedimentados, as ideias e ideologias predominantes na sociedade em determinado momento. A fase da implementação, a seu turno, é aquela em que os decisores aplicam ao caso prático, à realidade, à conjuntura, às necessidades, o que planejaram, isto é, o

182 momento em que aquilo que estava no campo das ideias enfrenta a realidade a que se aplicará, quando as decisões se traduzem em ação. É também quando a realidade confronta os decisores e suas escolhas em termos do processo decisório (Smith, Hadfield e Dunne, 2012, p. 148). Nesse sentido, se antes da PEI os decisores por vezes levavam alguns elementos como a independência, a autonomia, o universalismo em consideração na fase de elaboração, por vezes complicavam-se em projetá-los na implementação. Durante a vigência da PEI, ainda que por curto período, esses princípios foram efetivamente aplicados na implementação, como veremos adiante.

\section{Principais elementos da PEI}

A PEI iniciou-se nos primórdios do governo Jânio Quadros, com uma proposição por ele próprio apresentada em mensagem ao Congresso Nacional, em março de 1961 (Quadros, 1961). Fortemente influenciado pelo pensamento indepen- 
dentista de Afonso Arinos de Mello Franco, seu ministro de Relações Exteriores desde os primeiros momentos, Quadros relegava à política exterior um papel fundamental na busca pelo desenvolvimento do país, pela superação da pobreza e pelo alcance da justiça social. Compreendia que a diferenciação do mundo entre Norte e Sul era essencialmente econômica, mais que ideológica, e, por isso, considerava que o Brasil poderia e deveria estabelecer "contatos proveitosos" até mesmo com países de ideologias diversas, uma vez que essa atitude poderia contribuir para reduzir tensões internacionais e promover a paz (Arinos Filho, 2001, p. 156). Como diretriz sistemática, portanto, a PEI foi conceitual e estruturalmente para favorecer a independência política do Brasil e o desenvolvimento nacional. Ademais, empreendia aquilo que por alguns autores é conhecido como "desideologização da política externa”, termo que pode induzir à compreensão de que não havia uma ideologia pautando a formulação e a implementação das ações fundamentais. Ocorre que a PEI é absoluta e inquestionavelmente ideológica: independentismo, universalismo e desenvolvimentismo eram ideias-força essenciais para a própria concepção da PEI; o que se evitava era, na prática, a sujeição a peias ou a constrangimentos ideológicos limitadores dos voos que o governo procurava alçar: para universalizar, era necessário mesmo reconhecendo a realidade do mundo bipolarizado ideológica e economicamente - empreender estudos e projetos para ampliar mercados em todas as áreas do mundo, a despeito da escolha ideológica de cada uma. Essa universalização na seara comercial deveria ser acompanhada de uma cuidadosa aproximação política para que, mediante os laços inicialmente diplomáticos se pudesse fomentar frutíferas relações comerciais, com benefícios para o Brasil e para os outros países (Manzur, 2009a, passim).

Ressalte-se que, além dos princípios fundamentais elencados acima como base da ideologia da PEI, ainda a com- 
põem outros princípios da boa convivência internacional: a preservação da paz, o fortalecimento dos princípios da não intervenção e da autodeterminação dos povos, o fortalecimento do mercado externo e o apoio à emancipação dos territórios não autônomos. Com essas características, não seria surpreendente que a PEI fosse considerada avançada e bastante arrojada, tendo em vista as instituições políticas nacionais existentes no período. Há que se levar em conta, especialmente, o partido político que o alçou ao poder: a União Democrática Nacional (UDN), tradicional defensor das posições do chamado bloco democrático, de cunho conservador. Com isso, temas afeitos à inserção internacional do Brasil eram crescentemente comentados e discutidos em toda a sociedade, o que redundou em gradual envolvimento da opinião pública nos assuntos internacionais (Skidmore, 1975, pp. 245-46; Arinos Filho, 2001, pp. 142-45).

Havia unidade no governo Jânio Quadros quanto à PEI,

184 e essa unidade se projetou no governo Goulart, tendo em vista a sistematização da PEI como diretriz segundo orientação de San Tiago Dantas. Vejamos em seguida como se desenrolaram os eventos que culminaram com a deposição de Goulart e de que modo as movimentações da opinião pública sobre a política exterior do país contribuíram para esse processo.

\section{A PEI no governo Quadros}

Como visto, um dos pontos centrais da política externa de Jânio Quadros foi o estabelecimento de relações comerciais e diplomáticas seguindo o princípio universal: todos os países seriam potenciais parceiros comerciais e diplomáticos, independentemente de seus vínculos a blocos político-militares; isso significava, efetivamente, a abertura de relações com os países socialistas e com os novos Estados africanos, muitos dos quais vinham tornando-se independentes exatamente naquele momento. Jânio procurava, com isso, pro- 
jetar a liderança política do Brasil no hemisfério sul para, posteriormente, pleitear um tratamento privilegiado dos Estados Unidos. Essa postura nada tinha de neutralista, dado que não se rompia, naquele momento (e em qualquer momento da história brasileira), com a tradicional opção ocidental do país.

Em termos das relações multilaterais, bastante enfatizadas por Jânio, preconizava-se a importância dos organismos internacionais formados por países não participantes de nenhum dos grandes blocos. No que tange às relações no âmbito da América Latina, o Brasil procurou com Jânio uma aproximação cada vez maior, especialmente com a Argentina, cujo presidente (Frondizi) tinha uma proposta de política externa independente consoante à brasileira. Outro ponto relevante da política exterior empreendida no governo de Jânio Quadros foi o firme propósito de fazer valer o princípio de não intervenção estrangeira direta ou indireta em território cubano, bem como de não reconhecer qualquer governo resultante de ação desse tipo. A diplomacia brasileira defendeu a integridade política de Cuba e sua luta em prol da emancipação econômica, da afirmação nacional e do desenvolvimento, seguindo princípios da inserção internacional do Brasil evidenciados desde a Independência (Manzur, 2009a, p. 80).

Houve também uma busca de aproximação com a África, fundamentada nas afinidades culturais com aquele continente, dada a formação sócio-histórica brasileira. Isso permitiria, na visão do governo brasileiro, que o país fosse um interlocutor privilegiado dos países africanos nos foros internacionais. De qualquer modo, denotavam-se ainda ambiguidades no posicionamento brasileiro quanto aos processos de independências africanas. $\mathrm{O}$ discurso da diplomacia brasileira defendia, nos foros multilaterais, o anticolonialismo e os princípios da autodeterminação dos povos e da não intervenção; entretanto, na prática, o governo bra- 
sileiro era hesitante quanto a apoiar ou não o movimento independentista das colônias africanas; essa indefinição em especial decorria do apego às relações especiais com antigas metrópoles, tais como Portugal e França. No caso das colônias portuguesas, por exemplo, os representantes brasileiros eram instruídos a referir-se a elas como meras extensões ultramarinas do território de Portugal, o que deixava toda a discussão de sua independência a critério da metrópole. Entretanto, as ambiguidades da diplomacia brasileira situavam-se mormente na análise e na tomada de posição quanto aos processos de independência em si; uma vez selada a autonomia de qualquer país africano, o Brasil era geralmente uma das primeiras nações a afirmar e a reconhecer os novos Estados (Manzur, 2009a, passim).

Em linhas gerais, em suma, a política externa de cunho independentista proposta no governo Jânio Quadros abarcou os seguintes preceitos: preconizava o respei186 to aos compromissos e à projeção internacional do Brasil como país relevante no mundo livre ocidental; compreendia a ampliação do leque de contatos internacionais do Brasil como elemento fundamental para o desenvolvimento e para fortalecer a luta contra o subdesenvolvimento econômico; procurava manter posição conciliadora em prol da redução das tensões internacionais no plano regional e global; fomentava a expansão do comércio exterior em âmbito global; apoiava, no discurso diplomático, mormente nos fóruns multilaterais, o anticolonialismo e o anti-imperialismo; apoiava as Nações Unidas na defesa da paz internacional e da justiça econômica; propugnava fidelidade ao sistema interamericano com a continuidade e tentativa de expandir a abrangência dos princípios da Operação Pan-Americana (Manzur, 2009a, p. 81). Toda essa fundamentação projetou-se de modo quase inequívoco na política exterior empreendida por João Goulart, conforme se verá a seguir. 


\section{A PEI no governo de João Goulart}

A política externa empreendida no governo de João Goulart, conforme já mencionado, apontou para a continuidade em relação à de Jânio Quadros, especialmente no que tange aos fundamentos: universalismo, independentismo, desenvolvimentismo. Quando da renúncia de Quadros, Goulart encontrava-se em missão na China comunista, na tentativa de incrementar as relações comerciais e diplomáticas com aquele país, o que ilustra claramente as ações da diplomacia brasileira na moldura da PEI. Goulart manteve, com San Tiago Dantas como seu primeiro chanceler, a mesma tônica de tentar viabilizar o desenvolvimento do país por intermédio da política externa presente desde os anos 1930, mas a universalização por ele proposta tomava, segundo análise de algumas correntes da opinião nacional, matizes pró-comunistas.

\section{A Crise dos Mísseis em Cuba: um teste de fogo para os princípios da PEI}

Em 1962, fotos feitas por satélites norte-americanos mostraram construções que poderiam ser bases para mísseis em Cuba. Posteriormente, novas fotos atestaram uma movimentação de tropas do Exército Vermelho na ilha cubana, o que contribuiu para confirmar a hipótese de que a União Soviética estaria de fato enviando um grande arsenal para a ilha, como uma forma de represália pelo fato de os Estados Unidos haverem plantado mísseis balísticos na Turquia. Kennedy teria, em tese, duas opções de reação: a busca de solução diplomática, ou o confronto com a URSS. No entanto, por causa do fiasco da invasão pelos Estados Unidos da Baía dos Porcos, alguns representantes do Partido Republicano no Congresso estadunidense estavam paulatinamente transformando o assunto das relações com Cuba em um ponto fundamental das eleições (congressuais) que aconteceriam em 1962. Desse modo, Kennedy optou por uma resposta forte 
à URSS, em detrimento de uma solução diplomática: o bloqueio, que era sugerido e patrocinado ideologicamente por Bob Kennedy (irmão do presidente e attorney general) e por Theodore Sorensen, conselheiro especial da presidência (Allison e Zelikow, 1999, pp. 325-47).

Para empreender uma ofensiva contra Cuba, Kennedy procurou respaldo interno e em todo o continente americano. Nas reuniões de consulta ocorridas no período, evidenciaram-se duas posições conflitantes: a dos legalistas, entre os quais o Brasil, que se apegavam às normas da Carta da Organização dos Estados Americanos (OEA) e do Tratado do Rio de Janeiro, bem como aos princípios do Direito Internacional e da soberania, com o intuito de evitar qualquer tipo de intervenção militar em Cuba; e os aliados dependentes, especialmente aquelas repúblicas centro-americanas próximas a Cuba, que tinham vinculação mais estreita com os Estados Unidos e eram favoráveis 188 a medidas mais drásticas em relação ao regime cubano, pois sofriam a ameaça da proximidade com o país de Fidel Castro. Na VIII Reunião de Consulta dos Chanceleres Americanos, de 23 de janeiro a 2 de fevereiro de 1961, em Punta del Este, as duas correntes entraram em forte desacordo e a ideia de intervenção acabou saindo fortalecida, a despeito da oposição de alguns países, entre os quais o Brasil, que não acataram a proposta de exclusão de Cuba da OEA.

A posição do Brasil se definiu oficialmente no segundo dia, em discurso de San Tiago Dantas, em que se definiam as seguintes premissas: o governo brasileiro era contrário ao isolamento de Cuba, às sanções econômicas, tidas como infrutíferas, e às sanções diplomáticas, interpretadas como simplesmente simbólicas. O Brasil recusou-se a apoiar a exclusão de Cuba da OEA. A argumentação brasileira, sistematizada por Ilmar Penna Marinho na Reunião do Conselho da OEA, em 12 de fevereiro de 1962, tinha como funda- 
mento reconhecer a incompatibilidade da situação cubana com o sistema interamericano, tendo em vista que, para pertencer a ele, eram condições que o Estado geograficamente pertencesse ao continente americano e, ademais, que tivesse sua organização política com base no exercício da democracia representativa, no que Cuba não mais se enquadrava. Entretanto, o simples reconhecimento da referida incompatibilidade não poderia permitir, "nos termos da Carta de Bogotá, do Tratado do Rio de Janeiro e do Direito Internacional americano positivo" a exclusão de qualquer membro da OEA, dado que a Carta constitutiva da organização não previa, em suas cláusulas, a exclusão de um membro. Seria necessário, na argumentação do governo brasileiro, que se estabelecesse uma processualística específica que pudesse amparar juridicamente a exclusão de um país-membro do sistema interamericano. Penna Marinho afirmava, adicionalmente, que

[...] um diploma internacional desse tipo [que viesse a contemplar explicitamente a possibilidade de exclusão] teria, inclusive, a vantagem de impedir que, encorajada com o perigoso precedente cubano, a OEA, se venha arrogar, mais tarde, o papel de fiscal da situação política de cada país americano, violando, destarte, os princípios fundamentais de não intervenção e autodeterminação dos povos.

Com isso, o Brasil absteve-se de votar na questão (Bezerra, 2010, pp. 56-60).

Essa situação instigou grande movimentação no Brasil e em outros países do continente americano. A opinião pública brasileira podia, inclusive, acompanhar de perto os passos dados pelo representante brasileiro, dado que, no fim das reuniões, já de volta ao Brasil, San Tiago Dantas veio a público, em pronunciamento feito em cadeia nacional de televisão e rádio, esclarecer e defender o posicionamen- 
to brasileiro na questão cubana. E com as relações Brasil/ Cuba/Estados Unidos situa-se também o restabelecimento das Relações Diplomáticas com a URSS e os países do Leste Europeu como um dos temas que mais levantaram a opinião pública brasileira, acirrando os embates internos em torno de como se deveria dar a inserção internacional do Brasil naquele momento.

A relação entre opinião pública e política exterior, na vigência da PEI, foi portanto alçada a um plano de alta relevância. A política exterior é passível de controle e acompanhamento pela sociedade, em um processo de constante retroalimentação em que a sociedade influencia a elaboração das diretrizes da política exterior de um país e tal política, quando executada, sujeita-se ao escrutínio de diferentes grupos sociais. Essa constatação é bastante clara quando se leva em consideração a PEI e o modo como, com base nas diretrizes dela e de sua implementação, diferentes gru-

190 pos socialmente organizados movimentaram-se quanto ao modo de inserção internacional do Brasil.

\section{Influências mútuas entre opinião pública e política exterior durante a vigência da PEI}

Neste artigo, compreende-se opinião pública como o conjunto das diferentes correntes de pensamento expressas em um país em determinado período, entre as quais se encontram grupos de interesse, grupos esses políticos, econômicos e sociais (Manzur, 2009a, p. 29).

Em perspectiva histórica, a opinião pública não se confunde com a opinião da maioria ou a opinião de todos. É apenas a síntese de diversas opiniões expressas em determinado local, em determinado período. Sendo assim, para compreender como a opinião é formada ou informada pelos formuladores e condutores de política externa é mister levar em consideração os assuntos mais discutidos e sobre os quais se levantaram mais vozes internamente. 
No governo de Jânio Quadros, a opinião nacional se dividia em quatro correntes principais: liberal-associacionismo, liberal-nacionalismo, universal-independentismo e radical-nacionalismo, cada uma com características próprias, marcantes. É mister esclarecer que a definição dessas correntes não se baseia em filiação partidária, representatividade ou classe social, mas principalmente na abordagem sobre a maneira que se imaginava ideal para o Brasil se inserir no sistema internacional.

Em suma, o pensamento de cada uma das correntes pode ser apresentado da seguinte forma, de acordo com categorias analíticas (Manzur, 2009a, pp. 85-87). O liberal-associacionismo: tendência de opinião que priorizava as relações com o Ocidente, especialmente com os Estados Unidos, ao qual o Brasil deveria associar-se para barrar o avanço do comunismo, visto pelos partidários dessa corrente como o grande inimigo do país a ser combatido. Para o liberal-associacionismo, o contexto internacional encontrava-se clara e inquestionavelmente polarizado entre dois polos de poder: um dos lados defendendo os valores ocidentais e o outro representando uma ameaça a eles; assim, liberal-associacionistas valorizavam o engajamento brasileiro na luta entre Leste e Oeste e preconizavam a necessidade de inserção internacional do Brasil pela via do liberalismo associado a empresas e capital estrangeiros. Só com o apoio das potências ocidentais, mormente os Estados Unidos, o Brasil poderia alcançar o desenvolvimento. O liberal-nacionalismo, a seu turno, enfatizava o fato de que, a despeito de uma clara opção ocidental com base nas características históricas da formação brasileira, o país não teria necessidade de depender dos países mais ricos do Ocidente ou associar-se automaticamente a eles. Os liberal-nacionalistas temiam o avanço comunista, mas confiavam nas instituições democráticas para contê-lo, diferentemente dos liberal-associacionistas. O liberal- 
-nacionalismo considerava que o contexto internacional era separado em dois polos pela Guerra Fria mas, nacionalistas que eram, acreditavam na importância do Brasil como país relevante na luta contra a miséria e contra os males do comunismo. Assim como os liberal-associacionistas, pregavam a inserção liberal do Brasil no contexto internacional, mas não desconsideravam a possibilidade de intervenção do Estado na economia como regulador. Já o universal-independentismo preconizava uma inserção internacional independente e autônoma do Brasil, em um contexto de arrefecimento da rigidez bipolar, já evidenciado pelo que Vaïsse (2002, p. 57) compreende como coexistência pacífica entre as potências. Geralmente associado a uma tendência neutralista, o universal-independentismo manifestava-se, de fato, favorável ao alargamento das possibilidades internacionais do Brasil, com a universalização das relações econômicas e políticas do país. Não era 192 exatamente uma tendência neutralista, mas includente da diversidade, no sentido de abarcar uma expansão das relações internacionais do Brasil livre de constrangimentos ideológicos. Os universal-independentistas não temiam ameaças do comunismo porque acreditavam na força do ideal democrático. Esse ideal, a seu ver, apenas poderia ser fortalecido se o país se tornasse independente de blocos políticos, fosse capaz de definir suas diretrizes no campo internacional e pudesse estar distante das imposições advindas da vinculação a um bloco ou a outro. Na visão universal-independentista, restava claro que o Brasil não tinha tendências socializantes, mas o bloco ocidental deveria mesmo ser fortalecido, embora não pudesse sê-lo sem a cooperação dos países desenvolvidos, muitas vezes não dispostos a cooperar. Assim, deslocavam o eixo das discussões acerca da luta Leste-Oeste para Norte-Sul. E havia ainda o radical-nacionalismo, cuja característica mais marcante era uma visão de mundo anti-imperialista, que se revelava 
essencialmente anti-ianque. Na busca do desenvolvimento era necessário, segundo essa corrente, evitar a todo custo a subserviência em relação ao imperialismo da superpotência ocidental. Com isso, os radical-nacionalistas denunciavam com veemência a dependência brasileira em suas facetas mais evidentes, entre as quais as remessas descontroladas de lucros das empresas multinacionais ao exterior e a subordinação às determinações do FMI. Um ponto do radicalismo característico dessa corrente está no fato de que, para ela, qualquer situação seria preferível à dependência em relação aos Estados Unidos (considerada por eles muito mais perigosa que o próprio comunismo), até mesmo a possibilidade de relacionamento especial com os países comunistas e socialistas; com isso, despertava a ira dos conservadores e levava-os a associar os radical-nacionalistas ao comunismo internacional, o que na realidade não condizia com os posicionamentos nacionalistas. $\mathrm{O}$ radical-nacionalismo pleiteava reformas estruturais internas, cujos modelos bem poderiam ser colhidos nos países do Leste Europeu, mas poucos se vinculavam abertamente à ideologia comunista (Manzur, 2009a) .

Quando o presidente Jânio Quadros renunciou, seu vice, João Goulart, conforme já mencionado, estava em missão na China continental. Com o intuito de evitar um golpe preventivo à tomada de posse por Goulart, algumas forças sociais e políticas se mobilizaram para encontrar uma saída. O problema foi contornado com a aprovação, pelo Congresso, da emenda parlamentarista, que reduziu os poderes de Goulart. Como resultado, enfraqueceu-se a presidência, mas fortaleceu-se ainda mais o Parlamento, grande caixa de ressonância da opinião nacional. Além do Parlamento, vários meios de comunicação também espelhavam o embate abrangente sobre a maneira ideal de o Brasil inserir-se no contexto internacional. A opinião pública foi, desse modo, paulatinamente se polarizando e se reestruturando em duas 
principais megatendências (Manzur, 2009a, pp. 89-91): a liberal-ocidentalista, que abertamente propugnava a necessidade da defesa dos valores ocidentais como democracia e liberdade, da opção ocidental brasileira, do liberalismo como forma de inserção econômica e política do país no meio internacional, e até mesmo da ideologia cristã, associada de modo direto por essa corrente ao pensamento ocidental prevalente no Brasil. Os liberal-ocidentalistas manifestavam-se de modo claro contra a "infiltração comunista", do comunismo ateu, anticristão, que já estaria evidente até mesmo no governo, dado que muitos partidários dessa corrente concebiam a prática política do presidente Goulart como diretamente vinculada ao comunismo. Os liberal-ocidentalistas eram contrários às reformas (agrária, política e fiscal, entre outras) propostas pelo Executivo, associando-as ao perigo comunista, já que na visão das correntes oponentes, em especial dos reformistas, o modelo de reforma pode194 ria ser buscado até mesmo em países socialistas. Os liberal-ocidentalistas pretendiam impulsionar as relações especiais do Brasil com os Estados Unidos, pois acreditavam que só o liberalismo associado traria benefícios ao país no contexto que percebiam da bipolarização rígida evidente na Guerra Fria. Eram favoráveis à inserção do capital estrangeiro como forma mais adequada de capitalizar o país e favorecer o desenvolvimento. Já a nacional-revisionista, a seu turno, concebia como fundamental e premente a implementação de reformas na estrutura econômica, social e política brasileira. Conclamava a população, as classes políticas, as elites socioeconômicas do país a unir-se em favor da revisão da política interna e externa, especialmente nos tópicos que levavam o país à dependência. Os nacional-revisionistas mostravam-se contrários à vinculação associada e dependente a qualquer das potências mas, em geral, prefeririam um relacionamento especial com a União Soviética ao relacionamento com os Estados Unidos. Evitavam, contudo, a 
associação aberta com o comunismo, preferindo ter uma imagem afeita ao trabalhismo e ao socialismo. O maior inimigo a ser combatido, na visão nacional-revisionista, seria a ação imperialista norte-americana.

Goulart identificava-se com o revisionismo: "regulamentou a Lei de Remessa de Lucros; assinou um decreto em que se propunha a completa revisão de todas as concessões governamentais na indústria de mineração; assinou o decreto da Reforma Agrária e a encampação das refinarias de petróleo particulares, dentre outras medidas" (Manzur, 2009a, p. 285). Essa postura fortaleceu entre os liberal-ocidentalistas a percepção de que ele de fato estaria associado ao comunismo internacional e, com isso, perigos e ameaças à sociedade brasileira e ao mundo livre e liberal emanariam do próprio governo.

Do mesmo modo, a corrente nacional-revisionista também tinha sua parcela de descontentamento. Críticas constantes eram feitas a respeito do que os nacional-revisionistas consideravam uma adesão do governo ao receituário do FMI, às remessas de lucros desregradas que drenavam a economia nacional (portanto questionando os atrasos na votação da Lei de Remessas de Lucros), à capitulação em face dos financiamentos no âmbito da Aliança para o Progresso.

A situação se agravava a cada dia e a polarização das tendências de opinião quanto à inserção internacional do Brasil refletia esse agravamento. Esse processo culminou com a prevalência dos interesses da corrente liberal-ocidentalista que, com forte participação de representantes das elites militares econômicas e políticas, tomou a frente do golpe que instituiu o regime militar no Brasil.

$* * *$

Entre 1961 e 1964, estiveram à frente do governo os presidentes Jânio Quadros e João Goulart. Ressalvadas várias 
diferenças entre eles - no que respeita a características pessoais, políticas (eram de partidos e tendências diferentes, mas a lei eleitoral permitia essa composição), de percepção da realidade brasileira, como da própria administração de cada um -, alguns elementos comuns podem ser identificados na gestão deles. Em primeiro lugar, a manutenção, durante toda a vigência da PEI, dos princípios do universalismo, do independentismo e do desenvolvimentismo, princípios esses que favoreceram a unidade e a continuidade na política exterior do período de 1961 a 1964 e embasaram a proposta arrojada de relações internacionais sem constrangimentos ideológicos em um momento de Guerra Fria, no qual, para muitos, essa independência não seria viável, nem sequer possível. Em segundo, o envolvimento da opinião pública com assuntos de política exterior também foi inequívoco durante todo o período de vigência da PEI. Esse envolvimento é fruto da evolução de uma política populista 196 já identificável, por exemplo, com Getúlio Vargas e Juscelino Kubitschek, em anos anteriores. A noção, ainda que incipiente e não exatamente ilustrada de grande parte da população, da existência do perigo comunista inflamava os ânimos contra qualquer aproximação com países que não compusessem o conjunto do Ocidente.

Correntes de opinião enfrentavam-se e paulatinamente radicalizaram-se quanto à percepção que cada uma considerava adequada da inserção internacional do país. Nos anos finais do governo Goulart, os que preconizavam relações especiais com a potência norte-americana, o ocidentalismo, a liberalização do comércio afrontavam aqueles que, por outro lado, lutavam veementemente contra o "imperialismo ianque", a dependência em relação aos Estados Unidos, a favor do nacionalismo mesmo em política exterior, da autonomia internacional do Brasil, da abertura a relações mais próximas com países socialistas e comunistas. A polarização das tendências de opinião foi um dos fatores que contribuíram deci- 
sivamente para o golpe de 1964, neste prevalecendo os do primeiro grupo, os quais chamamos de liberal-ocidentalistas.

De fato, a conjuntura nacional da época, aliada a um contexto internacional em que o arrefecimento da rigidez bipolar já se iniciava, possibilitou o fortalecimento e a ampliação do espaço democrático interno e a expressão dos diferentes projetos que os grupos de esquerda e nacionalistas advogavam para a sociedade brasileira, tornando visíveis as contradições sociais e acirrando a luta político-ideológica. A intensa mobilização popular que caracterizou o período e foi crescente num clima político marcadamente anti-imperialista, que vigorou também em outros países da América Latina, estimulou a organização das forças sociais conservadoras que se sentiam perigosamente ameaçadas pelo avanço das reformas estruturais na sociedade a serem empreendidas em curto prazo. O fim do governo de João Goulart demonstrou que as dificuldades internas para administrar a crise brasileira eram tão grandes que a PEI não pôde ser levada adiante em sua integridade. Esse processo culminou com a deposição de Goulart, em 1964.

\section{Tânia Maria P. G. Manzur}

é professora adjunta do Instituto de Relações Internacionais da Universidade de Brasília (UnB).

\section{Bibliografia}

ALLISON, G.; ZELIKOW, P. 1999. Essence of decision: explaining the Cuban

Missile Crisis. 2. ed. New York: Longman.

ARINOS FILHO, A. 2001. Diplomacia independente: um legado de Afonso

Arinos. São Paulo: Paz e Terra.

ARNOLD, J. R.; WIENER, R. 2012. (eds.). Cold War: the essential reference guide. Santa Barbara, Califórnia: ABC-CLIO, LLC.

BEZERRA, G. H. M. 2010. Brasil-Cuba: relações político-diplomáticas no contexto da Guerra Fria. Brasília: Funag.

BONAVIDES, P.; AMARAL, R. 2002. Textos políticos da história do Brasil.

Brasília: Senado Federal. CD-ROM, v. 7. 
CERVO, A. L. 2008. Inserção internacional: formação dos conceitos brasileiros. São Paulo: Saraiva.

CERVO, A. L.; BUENO, C. 2011. História da política exterior do Brasil. 4. ed. Brasília: Ed. UnB.

DANTAS, S. T. 1962. Política externa independente. Rio de Janeiro: Civilização Brasileira.

FRANCO, A. da C. 2008. (org.). Documentos da política externa independente. Brasília: Fundação Alexandre de Gusmão, 2v.

HIRST, M. 1990. O pragmatismo impossível: a política externa do segundo governo Vargas (1951-1954). Rio de Janeiro: FGV, p. 6.

LESSA, A. C. 2008. "Há cinquenta anos a Operação Pan-Americana". Revista Brasileira de Política Internacional [on-line], v. 51, n. 2, pp. 5-7. Disponível em: <http://www.scielo.br/scielo.php?script=sci_ arttext\&pid=S0034-73292008000200001\&lng=en\&nrm=iso\&tlng=pt $>$. Acesso em: $11 \mathrm{dez} .2014$.

MANZUR, T. M. P. G. 1999. "Opinião pública e política externa do Brasil do Império a João Goulart: um balanço historiográfico”. Revista Brasileira de Política Internacional. [on-line]. v. 42, n. 1, pp. 30-61. Disponível em: <http:/ /www.scielo.br/scielo.php?script=sci_ arttext\&pid=S0034-73291999000100002\&lng=en\&nrm=iso $>$. Acesso em: 11 dez. 2014. . 2009a. Opinião pública e política exterior do Brasil (1961-1964). Curitiba: Juruá. . 2009b. "Interesse nacional, idealismo e realismo na política exterior norte-americana: um falso embate? O debate entre Woodrow Wilson e Theodore Roosevelt nas eleições de 1912”. In: DINIZ, E. (org.). Estados Unidos: política externa e atuação na política internacional contemporânea. Belo Horizonte: PUC-Minas, v. 1, pp. 71-90.

MCPHERSON, A. 2003. Yankee No! Anti-Americanism in U.S. - Latin American Relations. Cambridge: Harvard University Press.

MELLO E SILVA. A. de. 1992. A política externa de JK: a Operação PanAmericana. Rio de Janeiro: CPDOC.

MOURA, G. 1980. Autonomia na dependência: a política externa brasileira de 1935 a 1942. Rio de Janeiro: Nova Fronteira. 1983. "A Revolução de 1930 e a política externa brasileira: ruptura ou continuidade?” In: SEMINÁRIO INTERNACIONAL. A Revolução de 30. Brasília: Ed. UnB. . 1991. Sucessos e ilusões: relações internacionais do Brasil durante e após a Segunda Guerra Mundial. Rio de Janeiro: FGV.

MURESAN, M. 2008. "Romania's integration in Comecon. The analysis of 
a failure. The Romanian Economic Journal, ano XI, v. 30, n. 4, pp. 27-58. PALMER, G.; MORGAN, T. C. 2012. A theory of foreign policy. Princeton: Princeton University Press.

PINHEIRO, L. de A. 2004. Política externa brasileira. Rio de Janeiro: Jorge Zahar Editor.

QUADROS, J. 1961. "A nova política externa do Brasil”. Revista Brasileira de Política Internacional, Rio de Janeiro, ano IV, n. 16, pp. 150-56 dez.

SARAIVA, J. F. S. 1996. O lugar da África: a dimensão atlântica da política externa brasileira de 1946 a nossos dias. Brasília: Ed. UnB.

2001. (org.). Relações internacionais. Dois séculos de história. Entre a preponderância europeia e a emergência americano-soviética (18151947). Brasília: IBRI, 2v.

SKIDMORE, T. 1975. Brasil: de Getúlio a Castelo. Rio de Janeiro: Paz e Terra.

SMITH, S.; HADFIELD, A.; DUNNE, T. 2012. Foreign policy: theories, actors, cases. 2. ed. Oxford: Oxford University Press,

SOUTO MAIOR, L. A. P. 2001. "Brasil-Estados Unidos: desafios de um relacionamento assimétrico". Revista Brasileira de Política Internacional. v. 44, n. 1, pp. 55-68. Disponível em: <http://www.scielo.br/scielo. php?script=sci_arttext\&pid=S0034-73292001000100005\&lng=en\&nrm=i so>. Acesso em: $11 \mathrm{dez} .2014$.

THE COMINFORM: Minutes of the three conferences $(1947 / 1948 / 1949)$. 1994. Milano: Fondazione Giangiacomo Feltrinelli; Russian Centre of Conservation and Study of Records for Modern History.

TRUMAN, H. S. 1947. Special message to the Congress on Greece and Turkey: the Truman doctrine. March 12. In: PETERS, G.; WOOLLEY, J. The American Presidency Project. Disponível em: <http:/ /www.presidency. ucsb.edu/ws/?pid=12846>. Acesso em: $11 \mathrm{dez} .2014$.

VAÏSSE, M. 2002. As relações internacionais desde 1945. Lisboa: Edições 70. WATSON, A. 1992. The evolution of international society. London: Routledge. WEFFORT, F. 1980. O populismo na política brasileira. Rio de Janeiro: Paz e Terra. 


\section{A POLÍTICA EXTERNA INDEPENDENTE (PEI): ANTECEDENTES, APOGEU E DECLÍNIO}

TÂNIA MARIA P. G. MANZUR

Resumo: Este artigo analisa o período de 1961 a 1964, quando a sociedade brasileira vivenciou o processo de gestação, desenvolvimento, apogeu e declínio da Política Externa Independente (PEI). Na vigência das presidências de Jânio Quadros e, posteriormente, João Goulart, observa-se expressivo envolvimento da opinião pública com assuntos de política exterior, envolvimento esse que é fruto de um amálgama entre o populismo e o desenvolvimento e a disseminação dos meios de comunicação de massa, bem como ao aumento dos níveis de alfabetização da população brasileira, acompanhado da crescente urbanização. Alimentou-se um debate que evoluiu para embates de opinião sobre a política exterior do país. A paulatina polarização das tendências de opinião foi um dos fatores que contribuíram decisivamente para o golpe de 1964.

Palavras-chave: Política Externa Brasileira; Opinião Pública; Polarização; Golpe de 1964.

\section{BRAZILIAN INDEPENDENT FOREIGN POLICY: HISTORICAL ROOTS, APOGEE AND DECLINE}

Abstract: This article analyzes the development, apogee and rapid decline of Brazil's Independent Foreign Policy (1961-64), a period when it is possible to observe close and profound interactions between public opinion and the country's foreign policy. Back then, Brazilian politics on every sphere - domestic and international - was marked by populism which, allied to the fact that mass media and other resonance boxes of public opinion were arising and being strengthened in the country, helped create and develop the fundamental relations between public opinion trends and the directions taken by the government in the international arena. The 
gradual polarization of opinion trends in relation to the country's international insertion eventually led to the 1964 Coup d'Etat.

Keywords: Brazilian Independent Foreign Policy; Public Opinion; Polarization; 1964 Coup d'État. 